\title{
A case report of Acne Vulgaris: Treated by combination of Acupuncture Tania Hoque*
}

Assist. Prof. Skin \& VD Dept. Gonoshastho Somaz Vittik Medical College, Bangladesh.

Corresponding Author : TaniaHoque - Assist.Prof. Skin\&VDDept.Gonoshastho Somaz Vittik Medical College.Email:nurekiron58@gmail.com Received date: September 13,2018;Accepted date : September 28,2018; Published date: October 01,2018.

Citation for this Article: Tania Hoque. A case report of Acne Vulgaris: Treated by combination of Acupuncture. J. Dermatology and Dermatitis. Doi:10.31579/2578-8949/042

Copyright : @2018 Tania Hoque. This is an open-access article distributed under the terms of the Creative Commons Attribution License, which permits unrestricted use, distribution, and reproduction in any medium, provided the original author and source are credited.

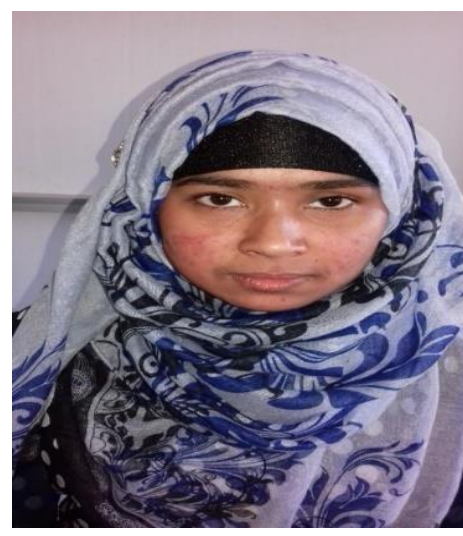

After 10days Treatments

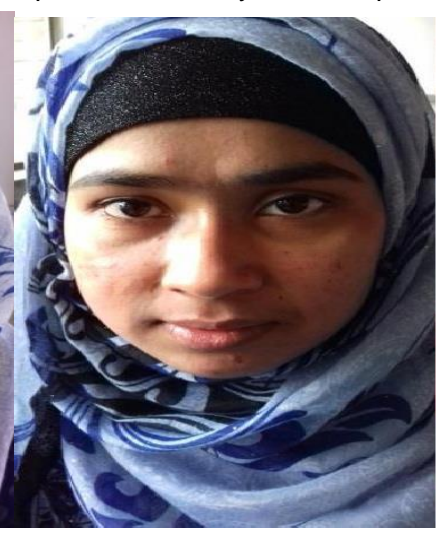

after 15 days Treatment

A 23years of female patient came at Gonosashthaya Somaj vittik Medical college, Savar 1yr back with the complains of -

- Multiple papulo-pustular scattered lesions over face, neck and back for 5 -6yrs

- She was diagnosed as a known case of Acne Vulgaris 2YRS back

- $\quad$ And treated here with anti-acne medicine for $1 \mathrm{yr}$.

Past history: She got no history of allergy, asthma

Personal history: She took lots of cosmetics and herbal products for her fairness.

She is married for 5yrs and have one female healthy child of 3yrs; she never took any contraceptive method.

Medical history: She took lots of antibiotics and anti-acne cream by the Dermatologist for 2yrs.

Family history: there was no history of acne disease to her family members

\section{Menstrual history:Regular}

On local examination: She got multiple papulo-pustular lesions over face, neck and back

Under Magnifying glass there were multiple black head and white head comedons ( which are the cardinal feature of acne vulgaris )

There was no pain and itching sensations.

\section{On Wood's Lamp Examination}

- There were multiple "Propionebacterium Acne" organism present over the acne comedons

- There were multiple hyperpigmentation after acne remission area

- There were also large pores due to acne scar.

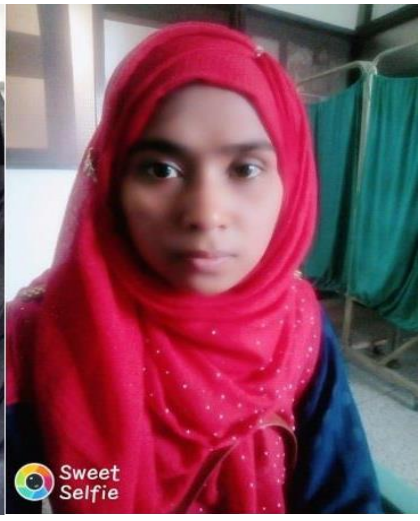

after 30 days treatment

On General examination : there was no abnormality detected

On Systemic examination : Her all the vital functions was normal

On Investigation :

1) CBC : Normal

2) Blood Sr. Testosterone: Normal

3) USG of whole abdomen: Normal

Treatment given for $1 \mathrm{yr}$ :

1) Anti-biotics like

Cap.Doxycyclin 50-100mg (orally)

Cap.Tetracyclin 500mg (orally)

Tab.Azythromycin 500mg (orally)

Eromycine lotion (locally)

Clindamycine lotion (locally)

\section{2) Anti-Acne like}

Adapolen cream

Benzyle Peroxidase cream

Retinoic acid cream

- Patient was treated by those medicine for $1 \mathrm{yr}$

- She cured within 6months but recurrent acne developed after stopping this treatment

- Then she was treated "Acupuncture Therapy" - 3days (one alternative day) in a week for one month with combination of local anti-acne medicine

- Photo of pt before and after treatment

Prognosis

$\sqcup$ After stopping of anti-acne and Acupuncture therapy for 1month, there was no occurrence of acne recurrence

$\sqcup$ There was brightness due to disappearance of hyperpigmentation.

$\sqcup$ There was improvement of acne scars also. 


\section{Discussion}

$\sqcup$ Acne is an annoying and often painful problem that affects millions of people each year

$\sqcup$ The extended use of antibiotics, there some studies that indicates that acne patients can build up a tolerance to antibiotics, making them less effective

A 2011study published in the Archives of Dermatology looked at 83 patients on Antibiotic acne medication and found that within 2months, the patients showed a $40 \%$ resistance to clindamycin, a $10 \%$ to tetracycline, and $44 \%$ to erythromycine.

\section{Why Acupuncture -> An alternative option?}

$\sqcup$ Acupuncture has been used to treat hundreds of conditions in traditional Chinese medicine

$\sqcup \quad$ There are numerous studies that prove that acupuncture is effective at improving acne symptoms

$\sqcup$ In a 2003 study published in inflammatory mediators, researchers looked at the anti-inflammatory properties of acupuncture

\section{Mechanism of Action of Acupuncture}

$\sqcup$ Acupuncture may have anti-inflammatory effects and fight acne due to the stimulation of beta-endorphins, substance P; CGRP and cytokine

$\sqcup$ Low-dose acupuncture should be more effective, to prevent the high concentration of CGRP in the body (which can lead to inflammation)

\section{Sources}

$\sqcup \quad$ http ://en.wikipedia.org/wiki/Benzoyl-Peroxidase

$\sqcup \quad$ http ://www.patient.co.uk/health/antibiotics tablets for acne.

- Acupuncture is believed to stimulate the nervous system and cause the release of neurochemical messenger molecules

- Acupuncture reduces acne inflammation by releasing vascular and immunomodulatory factors

- It enhances natural killer cell activities

- It increase local microcirculation to disperse swelling.

Acupuncture stimulate the lymphatic system which is essential for eliminating a variety of toxins from the body; these toxins when trapped in the body, can cause a number of physical ailments, including slow healing of wounds and scars in the formation of acne.

\section{Contraindication}

Only scars that are at least a month old should be treated with acupuncture, due to increased risk of infection.

The elderly, diabetics, cancer patients and tumors with neurological disorders require special care.

\section{I faced some problems}

$\sqcup \quad$ Most important is financial problem

$\sqcup \quad$ Afraid of needle

$\sqcup \quad$ Aggravation of acne after 1wk of acupuncture therapy

$\sqcup \quad$ Patients were almost students, so it's difficult to comeevery alternate day by giving absent to the school and college .

\section{Conclusion}

$\sqcup \quad$ We have discovered a new way how patient can finally get a clean, beautiful skin

$\sqcup$ Traditional Chinese medicine has many advantages and Acupuncture is an effective method how to get rid of acne with acne scars

$L$ I like to thank Prof,Dr. N.M Kiron Head of the Acupuncture Department Gonoshastho Somaz Vittik Medical College for his kind support to treatment by Acupuncture of those patients and give information about "Acupuncture treatment in Acne Vulgaris".

\section{Activators of Research.}

\section{Prof. Dr. N.M.kiron}

- Head of the Acupuncture Department.

- Gonoshastho Community Based Medical College \& Hospital .Bangladesh.

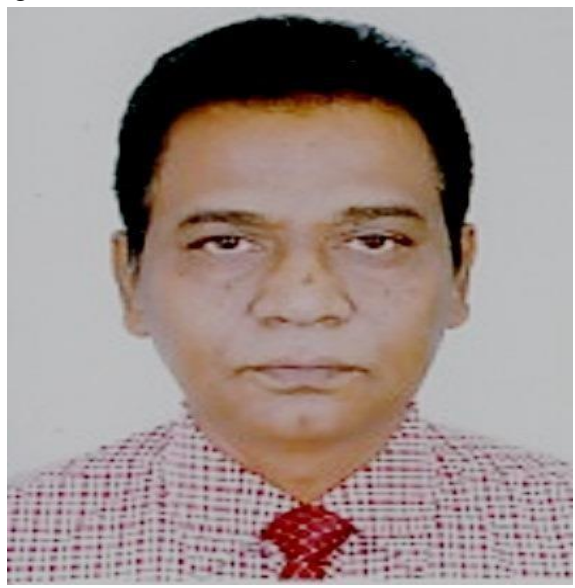

\section{Dr.Tania Houque}

- Asst. Professor Skin \& VD Department

- Gonoshastho Community Based Medical College Savar. Dhaka .Bangladesh. 